\title{
Pattern of presentation of idiopathic polypoidal choroidal vasculopathy in Ibadan, Sub-Saharan Africa
}

This article was published in the following Dove Press journal:

Clinical Ophthalmology

5 July 2013

Number of times this article has been viewed

\section{TS Oluleye \\ Y Babalola}

Retina and Vitreous Unit, Department of Ophthalmology, University of Ibadan and University College Hospital, Ibadan, Nigeria
Correspondence: TS Oluleye Retina and Vitreous Unit,

Department of Ophthalmology, University of Ibadan and University

College Hospital, Ibadan, Nigeria

Tel +234 8023265594

Email t_oluleye@yahoo.co.uk
Background: Idiopathic polypoidal choroidal vasculopathy is an abnormal choroidal vascular pathology similar to age-related macular degeneration. It may present with sudden visual loss from hemorrhagic retinal pigment epithelial detachment and breakthrough vitreous hemorrhage or with chronic recurrent episodes. The condition is not uncommon in the retina clinic at the University College Hospital, Ibadan, Sub-Saharan Africa. This study presents the pattern of presentation in Ibadan.

Methods: We review all cases of idiopathic polypoidal choroidal vasculopathy seen from 2007 to 2012 in the retina clinic at the University College Hospital, Ibadan, to determine the major pattern of presentations, available treatment modalities, and visual outcomes.

Results: Ten cases were seen during the study period. Their mean age was 58 years, with a male to female ratio of 1:4. The most common presenting complaint was sudden visual loss. Major examination findings were retinal pigment epithelial detachment, orange subretinal lesions, and breakthrough vitreous hemorrhage. The modalities of treatment available included vitrectomy to clear vitreous hemorrhage. Intravitreal bevacizumab reduced the height of the pigment epithelial detachment and cleared vitreous hemorrhage. Thermal laser was applied for extrafoveal lesions. Two patients with subfoveal lesions were referred abroad for photodynamic therapy. Visual outcome showed significant improvement in vitrectomized patients who presented with vitreous hemorrhage. Presenting vision of hand motion and light perception improved to vision ranging from counting fingers to 6/12 after vitrectomy.

Conclusion: Idiopathic polypoidal choroidal vasculopathy may not be uncommon in SubSaharan Africa. A high index of suspicion is warranted in the diagnosis so as to provide timely intervention.

Keywords: idiopathic polypoidal choroidal vasculopathy, retinal pigment epithelial detachment, presentations, Sub-Saharan Africa

\section{Introduction}

Idiopathic polypoidal choroidal vasculopathy (IPCV) is a choroidal vascular abnormality characterized by sudden visual loss from macular hemorrhage or breakthrough vitreous hemorrhage. Exudation is also common. The condition was often confused with wet age-related macular degeneration until Yannuzzi et al ${ }^{1,2}$ described it as a separate entity. Early reports described in Asians and patients of dark skin race showed a female preponderance, a younger age, an association with systemic hypertension, and presentation of orange retinal lesions and subretinal hemorrhagic detachment, ${ }^{3,4}$ but to the best of the authors' knowledge, not in Sub-Saharan Africans. This study describes the patterns of presentation in ten patients diagnosed with IPCV in Ibadan, Sub-Saharan Africa. 


\section{Materials and methods}

A retrospective review was done of 10 patients seen in the retina clinic at the Department of Ophthalmology, University College Hospital, Ibadan between 2007 and 2012. The retina register was opened in 2007 after subspecialization in the Department of Ophthalmology at this hospital. Case files of patients with a diagnosis of IPCV vasculopathy were retrieved and studied. The diagnosis was based on clinical findings of subretinal orange lesions, retinal pigment epithelial detachments, subretinal hemorrhagic detachments, and exudates in the absence of drusen, as described in previous reports. ${ }^{1-4}$ Information extracted from the case file included patient demographics, presenting complaints, and visual acuity. Others included fundus findings, treatment modalities, and visual outcome at 3 months. The data were analyzed as proportions and percentages.

\section{Results}

The results are summarized in Table 1.

\section{Discussion}

Idiopathic polypoidal choroidal vasculopathy was described by Yannuzzi et al in hypertensive African Americans with hemorrhagic retinal pigment epithelial detachment in the absence of drusen. ${ }^{1}$ The present study showed a female preponderance (male to female ratio, 1:4) in the fifth and sixth decades, in keeping with previous reports of younger age than in patients with age-related macular degeneration. ${ }^{4}$

In a previous report from our center, a total of 768 retinal cases were seen in the hospital over a 3-year period, of which 101 were diagnosed to have age-related macular degeneration, representing $14 \%$ of all retinal cases seen. The peak age was at least 60 years, and the male to female ratio was about 2:3. Wet age-related macular degeneration was seen in $40(40 \%)$ of cases. More females presented with wet age-related macular degeneration (26\% versus $14 \%$ ) and the intermediate form, while more males appeared to present with advanced dry agerelated macular degeneration $(12 \%$ versus $5 \%){ }^{5}$

Sudden visual loss was the commonest presentation in the present study. Bilateral disease occurs in about $70 \%$ of the cases. The main findings included breakthrough vitreous hemorrhage, subretinal orange lesions, and hemorrhagic retinal pigment epithelial detachment with subretinal exudates and blood.

The natural course (Figures 1, 2, and 3) of the disease includes chronic serosanguinous detachment with preserva-

Table I Pattern of presentation of idiopathic polypoidal choroidal vasculopathy in Ibadan

\begin{tabular}{|c|c|c|c|c|c|c|c|}
\hline Patient & $\begin{array}{l}\text { Age } \\
\text { (years) }\end{array}$ & Gender & Presentation & $\begin{array}{l}\text { Presenting VA } \\
(\mathrm{R} \text { and } \mathrm{L})\end{array}$ & Retina signs & Treatment & $\begin{array}{l}\text { Outcome } \\
\text { VA (R and L) }\end{array}$ \\
\hline I & 68 & $\mathrm{~F}$ & Sudden visual loss & $\begin{array}{l}R, 6 / 36 \\
L, 6 / 60\end{array}$ & $\begin{array}{l}\text { Peripheral exudates, } \\
\text { bilateral }\end{array}$ & - & $\begin{array}{l}\text { R, 6/36; } \\
\text { L, 6/60 }\end{array}$ \\
\hline 2 & 47 & $\mathrm{~F}$ & Sudden visual loss & $\begin{array}{l}\mathrm{R}, \mathrm{LP} \\
\mathrm{L}, 6 / 24\end{array}$ & VH, bilateral & $\mathrm{R}$ vitrectomy & $\begin{array}{l}\text { R, CF; } \\
\text { L, HM }\end{array}$ \\
\hline 3 & 47 & $\mathrm{~F}$ & Sudden visual loss & $\begin{array}{l}\mathrm{R}, \mathrm{HM} \\
\mathrm{L}, \mathrm{LP}\end{array}$ & Unilateral VH & $\mathrm{R}$, vitrectomy & $\begin{array}{l}R, 6 / 24 \\
L, L P\end{array}$ \\
\hline 4 & 55 & $\mathrm{~F}$ & Sudden visual loss & $\begin{array}{l}\mathrm{R}, \mathrm{CF} \\
\mathrm{L}, 6 / 9\end{array}$ & $\begin{array}{l}\text { VH, RPE detached } \\
\text { bilaterally }\end{array}$ & $\begin{array}{l}\text { R, vitrectomy } \\
\mathrm{L} \text {, Avastin }\end{array}$ & $\begin{array}{l}R, 6 / 12 \\
L, 6 / 36\end{array}$ \\
\hline 5 & 67 & $\mathrm{~F}$ & Sudden visual loss & $\begin{array}{l}R, 6 / 36 \\
L, H M\end{array}$ & $\begin{array}{l}\text { Bilateral VH, RPE } \\
\text { detachment, } \\
\text { scarred macula }\end{array}$ & L, Avastin & $\begin{array}{l}\mathrm{R}, \mathrm{HM} \\
\mathrm{L}, \mathrm{CF}\end{array}$ \\
\hline 6 & 59 & $M$ & Sudden visual loss & $\begin{array}{l}\text { R, HM; } \\
\text { L, NLP }\end{array}$ & Unilateral VH & Vitrectomy & $\begin{array}{l}\mathrm{R}, \mathrm{CF} \\
\mathrm{L}, \mathrm{NLP}\end{array}$ \\
\hline 7 & 63 & $M$ & Sudden visual loss & $\begin{array}{l}\text { R, HM; } \\
\text { L, NLP }\end{array}$ & $\begin{array}{l}\text { Unilateral VH } \\
\text { Scar, orange lesion }\end{array}$ & $\begin{array}{l}\text { Vitrectomy } \\
\text { PDT }\end{array}$ & $\begin{array}{l}\text { R, CF; } \\
\text { L, LP }\end{array}$ \\
\hline 8 & 56 & $\mathrm{~F}$ & $\begin{array}{l}\text { Recurrent sudden } \\
\text { visual loss }\end{array}$ & $\begin{array}{l}\mathrm{R}, \mathrm{HM} \text {; } \\
\mathrm{L}, 6 / 60\end{array}$ & $\begin{array}{l}\text { Bilateral RPE detachment, } \\
\text { Subretinal hemorrhage. } R \text {, } \\
\text { macular scar, orange lesion }\end{array}$ & Bevacizumab PDT & $\begin{array}{l}\text { R, CF; } \\
\text { L, } 6 / 60\end{array}$ \\
\hline 9 & 54 & $\mathrm{~F}$ & Sudden visual loss & $\begin{array}{l}R, 6 / 9 \\
L, 6 / 5\end{array}$ & $\begin{array}{l}\text { Unilateral extrafoveal } \\
\text { orange lesions, } \\
\text { hemorrhage, RPE } \\
\text { detachment }\end{array}$ & $\begin{array}{l}\text { Bevacizumab, focal } \\
\text { laser }\end{array}$ & $\begin{array}{l}\mathrm{R}, 6 / 9 \\
\mathrm{~L}, 6 / 5\end{array}$ \\
\hline 10 & 63 & $\mathrm{~F}$ & $\begin{array}{l}\text { Sudden bilateral } \\
\text { visual loss }\end{array}$ & $\begin{array}{l}\mathrm{R}, \mathrm{HM} \\
\mathrm{L}, \mathrm{CF}\end{array}$ & $\begin{array}{l}\text { Orange lesions, RPE } \\
\text { detachment, macular } \\
\text { exudates }\end{array}$ & Bevacizumab & $\begin{array}{l}\mathrm{R}, \mathrm{CF} \\
\mathrm{L}, \mathrm{CF}\end{array}$ \\
\hline
\end{tabular}

Abbreviations: R, right; L, left; HM, hand motion; CF, count fingers; LP, light perception; NLP, nil light perception; PDT, photodynamic therapy; RPE, retinal pigment epithelium; VH, vitreous hemorrhage; VA, visual acuity. 


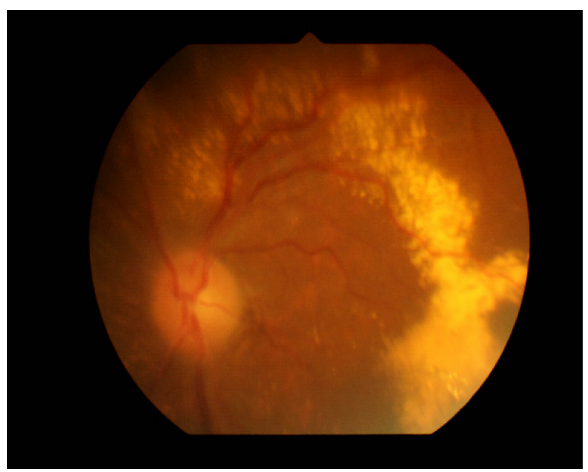

Figure I Idiopathic polypoidal choroidal vasculopathy with chronic subretinal exudate in a 68-year-old woman (patient I).

tion of vision. Other patients had hemorrhagic foveal detachment or chronic macular degeneration resulting in profound visual loss. The presentation usually is that of sudden visual loss, some (Figure 2) with a chronic course, some with recurrences, and 50\% with favorable visual outcomes. ${ }^{4,6}$

Idiopathic polypoidal choroidal vasculopathy is characterized by vascular aneurysmal lesions with interconnecting branches of vessels terminating in polyps. These polyps are prone to developing multiple, recurrent, serosanguinous retinal pigment epithelial detachment and neurosensory retinal detachment due to leakage and/or hemorrhage from the abnormal choroidal vascular lesions. ${ }^{1,2,4}$

Reported retinal findings include hemorrhagic detachment in about $75 \%$ and exudative findings in $25 \%{ }^{6}$ The present study showed hemorrhagic detachment in about
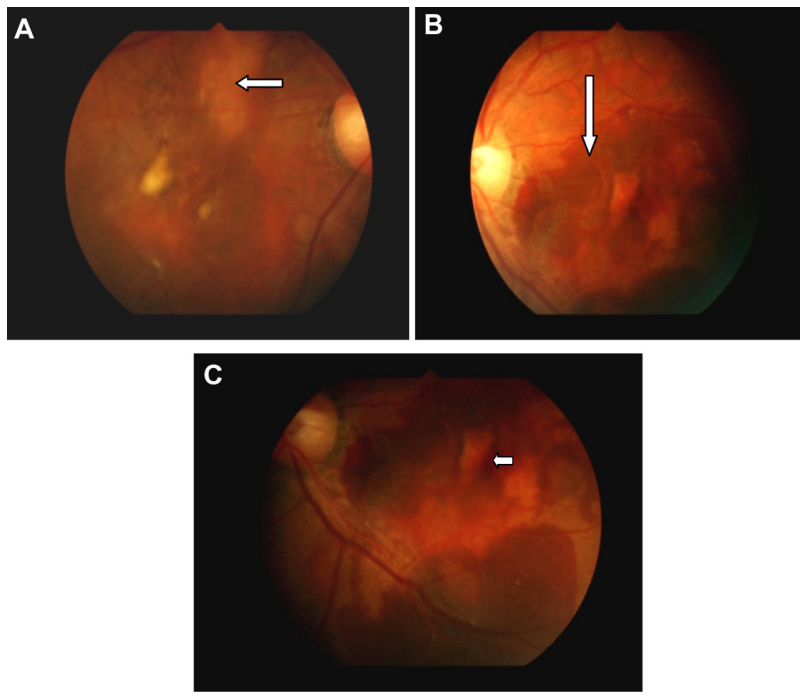

Figure 2 Fundus findings in patient 8 with idiopathic polypoidal choroidal vasculopathy. Right eye (A) with resolved subretinal blood and macular degeneration. (A) subretinal orange lesions (medium arrow); The left eye (B) shows fresh subretinal hemorrhage (long arrow); and (C) retinal pigment epithelial detachment (short arrow). Note the absence of drusen seen in age-related macular degeneration.

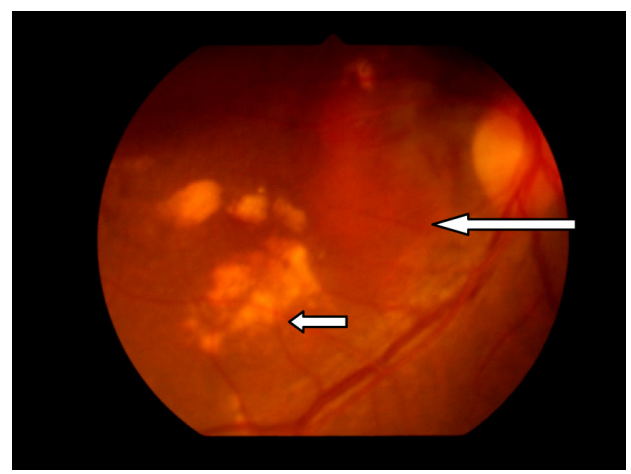

Figure 3 Patient 10 with idiopathic polypoidal choroidal vasculopathy. Orange subretinal lesion (long arrow) and subretinal exudates (short arrow).

$90 \%$ of cases, with breakthrough vitreous hemorrhage in $50 \%$ of cases.

The diagnosis of IPCV should be suspected in the presence of hemorrhagic or exudative retinal pigment epithelial detachments in the absence of drusen. However, the definitive diagnosis is established using indocyanine green angiography. This demonstrates the branching vascular network originating from choroidal circulation terminating in aneurysmal dilatation. Indocyanine green angiography uses infrared rays, hence its ability to detect the lesion under blood as opposed to fundus fluorescein angiography. ${ }^{7}$ Indocyanine green angiography studies showed two types of aneurysmal dilatation, ie, the solitary lesion and clusters resembling grapes. The latter is associated with recurrent bleeding and a poor visual prognosis. ${ }^{3}$ Indocyanine green angiography and optical coherence tomography are not available in our center, so the diagnosis was based on clinical findings.

Treatment modalities for IPCV include observation for extrafoveal lesions. Thermal laser is suggested for extrafoveal lesions threatening the fovea. Photodynamic therapy has been reported to be effective for subfoveal lesions by causing occlusion of the abnormal choroidal vasculature with improvement in vision. ${ }^{8-14}$ In the present study, vitrectomy was performed to clear breakthrough vitreous hemorrhage with improvement in vision. Intravitreal bevacizumab helped in clearing vitreous hemorrhage and reducing the height of pigment epithelial detachment. Intravitreal bevacizumab has been demonstrated to be beneficial in IPCV..$^{15}$ Two of our patients were referred abroad for photodynamic therapy.

Visual outcome in the present study showed significant improvement in vitrectomized patients with vitreous hemorrhage. Presenting vision of hand motion and light perception improved to vision ranging from counting fingers at one meter to 6/12 after vitrectomy. Intravitreal bevacizumab 
was administered to five patients and found to stabilize vision.

\section{Conclusion}

IPCV is not uncommon in Ibadan, Sub-Saharan Africa.

Patients presenting with sudden visual loss, vitreous hemorrhage, retinal pigment epithelial detachment, and subretinal exudation in the absence of drusen, should raise an index of suspicion in ophthalmologists in SubSaharan Africa.

\section{Acknowledgment}

The authors thank the Juvenile Open Angle Glaucoma Study Group for the use of their retinal camera.

\section{Disclosure}

The authors declare that no conflict of interest is associated with this study.

\section{References}

1. Yannuzzi LA. Idiopathic polypoidal choroidal vasculopathy. Paper presented at the Macula Society Meeting, February 5, 1982, Miami, FL.

2. Yannuzzi LA, Sorenson J, Spaide RF, Lipson B. Idiopathic choroidal vasculopathy. Retina. 1990;10:1-8.

3. Uyama M, Matsubara T, Fukushima I, et al. Idiopathic polypoidal choroidal vasculopathy in Japanese patients. Arch Ophthalmol. 1999;117: 1035-1042.

4. Yannuzzi LA, Ciardella A, Spaide R, Rabb M, Freund KB, Orlock D. The expanding clinical spectrum of idiopathic polypoidal choroidal vasculopathy. Arch Ophthalmol. 1997;115:478-485.
5. Oluleye TS. Is age related macular degeneration a problem in Ibadan, Sub Sahara Africa. Clin Ophthalmol. 2012;6:561-564.

6. Ahuja RM, Stanga PE, Vingerling JR, Reck AC, Bird AC. Polypoidal choroidal vasculopathy in exudative and hemorrhagic pigment epithelial detachments. Br J Ophthalmol. 2000;84:479-484.

7. Spaide RF, Yannuzzi LA, Slakter JS, Sorenson J, Orlach DA. Indocyanine green video angiography of idiopathic choroidal vasculopathy. Retina. 1995;15:100-110.

8. Spaide RF, Donsoff I, Lam DL, et al. Treatment of polypoidal choroidal vasculopathy with photodynamic therapy. Retina. 2002;22: 529-535.

9. Chan WM, Lam DS, LaiTY, et al. Photodynamic therapy with verteporfin for symptomatic polypoidal choroidal vasculopathy: one-year result of a prospective case series. Ophthalmology. 2004;111:1576-1584.

10. Quaranta M, Mauget-Faysee M, Coscas G. Exudative idiopathic polypoidal choroidal vasculopathy and photodynamic therapy with verteporfin. Am J Ophthalmol. 2002;134:277-280.

11. Rogers AH, Greenberg PB, Martidis A, Puliafito CA. Photodynamic therapy of polypoidal choroidal vasculopathy. Ophthalmic Surg Lasers Imaging. 2003;34:60-63.

12. Lee SC, Seong YS, Kim SS, Koh HJ, Kwon OW. Photodynamic therapy with verteporfin for polypoidal choroidal vasculopathy of the macula. Ophthalmologica. 2004;218:193-201.

13. Mauget-Faÿsse M, Quaranta-El Maftouhi M, De La Marnièrre E, Leys A. Photodynamic therapy with vertoporfin in the treatment of exudative polypoidal choroidal vasculopathy. Eur J Ophthalmol. 2006;165:695-704.

14. Hussain N, Hussain A, Natarajan S. Role of photodynamic therapy in idiopathic polypoidal choroidal vasculopathy. Indian J Ophthalmol. 2005;53:101-104

15. Lai TY, Chan WM, Liu DT, et al. Intravitreal bevacizumab (Avastin) with or without photodynamic therapy for the treatment of polypoidal choroidal vasculopathy. Br J Ophthalmol. 2008;92:661-666.
Clinical Ophthalmology

\section{Publish your work in this journal}

Clinical Ophthalmology is an international, peer-reviewed journal covering all subspecialties within ophthalmology. Key topics include: Optometry; Visual science; Pharmacology and drug therapy in eye diseases; Basic Sciences; Primary and Secondary eye care; Patient Safety and Quality of Care Improvements. This journal is indexed on Submit your manuscript here: http://www.dovepress.com/clinical-ophthalmology-journal

\section{Dovepress}

PubMed Central and CAS, and is the official journal of The Society of Clinical Ophthalmology (SCO). The manuscript management system is completely online and includes a very quick and fair peer-review system, which is all easy to use. Visit http://www.dovepress.com/ testimonials.php to read real quotes from published authors. 